\title{
RESENHA
}

\section{Nietzsche e a crise dos valores}

\section{Nietzsche and the crisis of values}

\author{
Lairton TRES*
}

Resumo: Esta resenha de parte da obra "Nietzsche", do autor Osvaldo Giacóia Júnior, quer nos colocar diante de uma reflexão a respeito de uma das crises que envolvem a humanidade: a crise de valores. Com a Modernidade, as relações humanas sofrem grandes modificações. Os sujeitos e a natureza passam a serem tratados como objetos; deixa-se de lado a preocupação com o ser, priorizando-se o ter. Surge um novo deus, capaz de guiar o seu próprio destino, sem se importar com valores de bem e mal: o homem. Como resultado desse processo, prejudica-se a natureza, na qual estão incluídos os demais seres humanos. Cabe, pois, à educação a tarefa de auxiliar no processo de reversão da crise estabelecida, através da luta pelo esclarecimento dos sujeitos. Assim será possível levá-los ao entendimento da realidade que os cerca para que, com isso, percebam a importância do significado dos valores que se perderam - a Verdade, a Justiça, o Bem e a Virtude - e possam resgatá-los para dar um novo rumo à humanidade e possibilitar melhores condições de vida a todos os seres que compõem o planeta.

Palavras-chave: crise de valores, esclarecimento, educação, educação ambiental

Abstract: This review of part of the work "Nietzsche" by Osvaldo Giacóia Júnior, intends to make us reflect on one of the crises envolving mankind: the crisis of values. With the advent of the modern era, human relationships have gone through great changes. People and nature have begun to be treated as objects; concern with the self is set aside, priority now given to 'having'. A new god appears, man, capable of guiding his own destiny, giving little importance to values such as good and evil. This process results in damage done to nature where all human beings are included. Therefore, education now

\footnotetext{
*Especialista em Engenharia Ambiental pela UPF. Email: lairtontres@bol.com.br
}

Olhar de professor, Ponta Grossa, 8(1): 187-192, 2005. 
has the task of helping to revert this crisis, now fully established, by enlightening the population. In this way it will be possible to make them understand the reality that surrounds them so that they become aware of the meaning of the values that have been lost - Truth, Justice, Goodness and Virtue - and may redeem them to give a new meaning to mankind and allow for a better standard of life for all beings living on this planet.

Key words: crisis of values, enlightening, education, environmental education

O autor Oswaldo Giacóia Júnior, em sua obra "NIETZSCHE”, de uma forma simples, sem perder a profundidade, procura retratar o pensamento nietzschiano e as suas contribuições para a educação. Nesses escritos, Giacóia refere-se a várias outras obras de Nietzsche, apontando pequenas sínteses das idéias que compõem o pensamento do filósofo. Esclarece o que os termos mais freqüentemente usados por Nietzsche querem dizer. Oswaldo Giacóia Júnior é bacharel em Direito (USP), Mestre em Filosofia (PUCSP), Doutor em Filosofia pela Freie Universität Berlin e professor livre-docente do Departamento de Filosofia da Universidade Estadual de Campinas (Unicamp).

Friedrich Wilhelm Nietzsche (1844-1900) nasceu na Alemanha e com 25 anos foi professor universitário. Destacou-se nos estudos filológicos, referentes às línguas, mas dando a esses estudos um caráter filosófico. Inaugurou um estilo novo na Filosofia, o estilo aforista. É considerado crítico da metafísica e rompe com a idéia de desenvolvimento lógico claro, de início, meio e fim. Salta de um tema para outro diferente, baseia-se em argumentações diferentes e caracteriza-se também pela ironia aos filósofos dogmáticos, afirmando que a erudição é a incapacidade de pensar. Destaca sua crítica à Filosofia Metafísica e aos Filósofos Modernos.

O livro é subdividido em sete capítulos além da introdução, que trata de uma explicação do porquê ler Nietzsche hoje. Nos capítulos são desenvolvidos os seguintes temas: A crise dos valores; Nietzsche e o fim da metafísica; $\mathrm{O}$ jovem Nietzsche; Uma filosofia para espíritos livres; A derradeira filosofia, ou como tornar-se o que se é; Breve história da recepção da obra de Nietzsche e dados biográficos.

É objetivo deste trabalho fazer uma resenha crítica do capítulo 1 da referida obra, que tem com título "A crise dos valores", buscando aproximar o tema à Educação Ambiental, que está atualmente fundamentada em concepções que visam ao esclarecimento do motivo de se manter uma boa relação entre os seres humanos e a natureza, e com os humanos entre si. Quem sabe, é preciso

Olhar de professor, Ponta Grossa, 8(1): 187-192, 2005. 
resgatar o sentido dos valores, que muito se perderam com o desenvolvimento da sociedade moderna, e que foram instrumentalizando as relações humanas, naturais e sociais.

O pensamento filosófico de Nietzsche registra e também antecipa questões referentes ao nosso século. "Sua ambição é realizar um diagnóstico fiel da situação do homem moderno". (p. 16). Destaca que, com o Iluminismo, passamos a nos julgar liberados da ignorância e da superstição. "Confiamos na utilização industrial, na ciência e na técnica e acreditamos que, assim, podemos desvendar os segredos de todo o universo e construir uma sociedade expurgada de todas as formas de opressão, violência e exploração". (p. 16). Nietzsche destaca isso porque acredita que se somos devotos do deus Logos, ou seja, da razão e da racionalidade. Supõe que, a partir desse fato, a vida, as relações humanas com os outros seres vivos possam ocorrer da melhor forma possível.

Ao se dar conta de seu otimismo desenfreado, o filósofo percebe um lado obscuro, um avesso sombrio: "o mesmo progresso conduz inexoravelmente à exaustão dos valores herdados da tradição, à sua impossibilidade de dar sustentação a futuros projetos viáveis, no campo quer do conhecimento, quer da ética, quer da política”. (GIACÓIA JÚNIOR, 2000, p. 17). A razão que deveria conduzir o homem a aplicar os bons valores parece não conseguir guiá-lo para isso. A vontade de poder conduz o homem, tornando-o cada vez mais o dono de si e o senhor do mundo. Um deus, capaz de criar e recriar o que bem quiser.

Para Nietzsche, os valores como a Verdade, Falsidade, Justiça, Bem, Mal e Virtude foram relativizados como conseqüência do progresso do conhecimento, gerando o que ele considera como a crise dos valores. A saída para essa crise não seria justificar ou condenar esse estado das coisas, mas, constatar $o$ problema, o que caberia aos filósofos.

Constatar a perda de validade dos valores morais não deveria ser hoje tão somente tarefa dos filósofos, mas, pelo menos daqueles mais instruídos, envolvidos pela cultura, apesar de nem sempre o saber e a cultura adquirida em bancos escolares se sobrepor às culturas originais de um povo: é este que, muitas vezes, nos dá grandes lições de vida, de valores, de respeito e dignidade para com os outros e a natureza. Porém, subentende-se que aqueles mais instruídos, que avançaram mais no conhecimento e no saber, que constituem hoje o homem moderno, deveriam ser os grandes exemplos de justiça, de verdade, de virtudes e de bem. Só que nem sempre isso acontece; os interesses pessoais acabam gerando situações de falsidade e maldade, daqueles que poderiam contribuir muito para a defesa da igualdade de direitos em favor da vida.

Para Nietzsche, "toda tentativa de negar essa condição de constatação do problema representa não apenas uma desonestidade intelectual e moral, mas, sobretudo, o risco de catástrofe; ou seja, a possibilidade de que o esvaziamen- 
to de valores autênticos nos conduza de volta à barbárie, à destruição daquilo que de mais precioso a humanidade conquistou ao longo da história: a dignidade da pessoa humana" (op cit, p. 17).

Em muitas situações de depredação da vida nos intrigamos e nos questionamos se ainda será possível resgatar a dignidade humana. No entanto, ainda temos bons exemplos de solidariedade que nos fazem refletir e pensar que nem tudo está perdido e que se mais mãos se estenderem, seguindo os bons exemplos, poderemos irradiar o mundo com a paz, incluindo nessa ação cada um que hoje se encontra à margem da sociedade. Sabemos que a tarefa é árdua demais, que as lutas contra as mega-potências são intensas e que, talvez, o sonho de dignidade para todos seja uma grande utopia. Porém, apesar disso tudo, não podemos deixar de constatar os fatos e, quem sabe, dessa forma, mexer com as consciências mais duras, podendo assim lapidá-las na melhor de todas as formas, o bem.

Diante disso, Nietzsche - com esta vontade de mostrar a todos esses fatos - dedicou sua vida a realizar três tarefas principais: "compreender a lógica deste movimento contraditório, denunciar todas as formas de mistificação e destruir os falsos ídolos". (op cit, p. 17). Queria compreender a lógica do movimento contraditório, como o bem e o mal, a verdade e a falsidade, que foi se constituindo ao longo do progresso do conhecimento e ocasionando a perda da consistência dos valores absolutos, para então denunciar todas as formas de mistificação que acabam obliterando a visão de perigo da própria condição humana. E, por fim, desejava destruir os falsos ídolos que regem a sociedade moderna - os valores mais venerados pelo homem moderno - para que, a partir disso, se pudesse pensar novos valores e abrir novos horizontes para a experiência humana na história.

A obra de Nietzsche submete uma crítica impiedosa a todas as esferas da cultura e exige do homem moderno a tomada de consciência das possibilidades de seu saber e agir. Coloca questões que até hoje prosseguem conosco e que se tornam a cada dia ainda mais necessárias para o resgate da dignidade nas relações da vida e com as mais variadas formas de vidas do planeta.

Em um dos seus mais célebres textos, Nietzsche coloca em cena o drama de nossa condição, ao falar de um homem louco que sai pela manhã com seu candeeiro pela cidade à procura de Deus, provocando gargalhadas daqueles que não acreditavam em Deus. "Para onde foi Deus? Nós o matamos, vós e eu!" (op cit, p. 18). Ao declarar isso, o homem louco continua se expressando, manifestando a morte de Deus provocada pelo homem, pois quem hoje domina é o homem, o senhor do universo, capaz de controlar as ações terrenas. Não somos nós, humanos, os próprios deuses? Até onde o poder da humanidade alcança? Por quanto tempo dura esse poder? Sabe-se que "sempre quem tenha 
apenas nascido depois de nós pertence, por causa deste feito, a uma história mais elevada do que foi toda história até agora!" (op cit, p. 19). O homem se sente um deus. Assim, o homem louco encerra dizendo: "O que são, então, as igrejas, se não criptas e mausoléus de Deus?"1

Nesse trecho do aforismo "O homem louco", citado no primeiro capítulo, Nietzsche nos remete à morte de Deus. Sua crítica está no fato daquilo que os homens fizeram com Deus, transformando-o, muitas vezes, num deus de interesses próprios, no seu deus. Descreve o sentimento de abandono e o vazio opressivo que envolve a consciência do homem moderno. A vitória da ciência contra a ignorância nos trouxe muitos benefícios, mas "nós homens modernos, não estávamos conscientes da dimensão do nosso próprio feito e nada sabíamos da tragédia que desencadeáramos nela, precipitando nosso mundo" (op cit, p. 20).

Em meio ao avanço da ciência, à velocidade da informação e à difusão do conhecimento, o homem moderno vai se instalando e, também, se perdendo diante de tantas coisas novas que vão sendo superadas dia após dia. Da revolução na vida, muito crescemos, muito evoluímos e, ainda, estamos vivendo muito mais do que vivíamos antes. Mas de que jeito? Com que condições e oportunidades? Em que tipo de deus estamos crendo hoje? Onde ficaram os valores e a ética da vida?

Parece que o desafio está em parar para nos darmos conta de que a crise dos valores está muito presente nas nossas relações sociais, educacionais, políticas e ecológicas. Todavia, dar-se conta somente, não basta. É preciso dar um passo a mais e, como o próprio Nietzsche (apud GIACÓIA JÚNIOR, 2000, p. 58) diz, "ser ponte, e não um fim: o que se pode amar no homem é que ele é uma passagem e um crepúsculo".

Em seu impulso crítico levado ao extremo, esse autor é filósofo que marca a modernidade demonstra que, se quisermos, poderemos ser pontes carregadas de virtudes, de bem, de verdade, de justiça e, num gesto de solidariedade, estender a mão aos que mais necessitam. E, assim, resgatar a dignidade das pessoas e dos demais seres vivos, animais e vegetais, que compreendem a grande teia da vida, dos quais se sabe que dependemos para garantir a sobrevivência da espécie humana, bem como a do planeta.

Ao refletir sobre esses aspectos, apontados também como princípios de uma educação ambiental que nos considera como parte de uma mesma natureza, entendemos que a educação pode ser a grande aliada nesse processo de transformação social através da recuperação dos valores. Cabe aos educado-

${ }^{1}$ NIETZSCHE, A Gaia Ciência; aforismo 125: O homem louco. Tradução de O. Giacóia Júnior. In: GIACÓIA JÚNIOR, O. Nietzsche. São Paulo: Publifolha, 2000.

Olhar de professor, Ponta Grossa, 8(1): 187-192, 2005. 
res ajudar a romper com a crise dos valores que envolve a humanidade e resgatar a ética da vida. Esse é o grande desafio que se faz a eles; mas, para que tal resgate aconteça, é preciso levar os sujeitos ao esclarecimento de si mesmos.

\section{REFERÊNCIA}

GIACÓIA JÚNIOR, O. Nietzsche. São Paulo: Publifolha, 2000

Encaminhado em 21/03/05

Aceito em 13/05/05 